\title{
Reforma ampla
}

\author{
PEDRO DE CAMARGO NETO
}

$\mathrm{Q}$ UEM SÃO OS excluídos do campo? Para responder esta pergunta, é preciso antes de mais nada conhecer as características do empobrecimento rural e do fluxo migratório.

Concentremos inicialmente a atenção no Pontal do Paranapanema. Encontramos nesta região do Estado de São Paulo grande tensão social. Quem é o semterra do Pontal? Que tipo de apoio recebeu na última década? Quais foram as políticas públicas que afetaram sua condição econômica? Que tipo de investimentos sociais foram ali realizados?

Esta região foi, no passado, grande produtora de algodão. Assistimos nos últimos anos a queda abrupta dessa cultura. Junto com a queda de produção, caiu o emprego rural. Quem perdeu trabalho? O algodão no Pontal era uma cultura de pequenos. Agricultores de pequena propriedade, arrendatários, meeiros, parceiros, além do trabalhador rural volante, o bóia-fria, foram os primeiros a sentir a derrocada da produção do algodão.

O Brasil passou de exportador de algodão à condição de maior importador mundial desta fibra. $\mathrm{O}$ algodão do Pontal foi o primeiro a cair. A decadência dessa lavoura teve reflexos sociais importantes. Quais as políticas públicas que afetaram negativamente a produção de algodão? $\mathrm{O}$ que foi feito de positivo para apoiar a produção? É preciso analisar as causas do empobrecimento rural para elaborar as políticas que tratarão dos efeitos.

O esforço público de apoio ao pequeno produtor, para que mantenha índices de produtividade e eficiência compatíveis com uma economia de mercado em acelerado processo de globalização, deve incluir a educação tecnológica ou extensão rural. Sem polemizar, pode-se afirmar que essa política pública foi e continua sendo medíocre, não só no Pontal como no resto do Brasil.

O seguro climático, as intervenções de apoio aos preços mínimos na colheita, o crédito rural para custear a produção e para realizar investimentos em aumentos de produtividade, mais do que medíocres foram, muitas vezes, extremamente negativos. O seguro Proagro não foi honrado. Os preços mínimos foram muitas vezes manipulados. O crédito rural, além de juros exorbitantes, sofreu os impactos das alterações de índices de correção a cada plano econômico, desbalanceando ativos e passivos, forçando a inadimplência.

Foi, porém, na política de comércio exterior que o algodão sofreu seu maior revés. Isto exigiu uma intervenção do poder público, que não ocorreu. Não houve 
produtividade de sobra para suportar as ações, e a falta de ações, do governo. A abertura foi total, com alíquota de imposto de importação de $2 \%$. A abertura foi irrestrita, com negligência ao tratar das importações de países que subsidiam sua produção. A abertura foi incentivada, com a captação de recursos financeiros no exterior por meio das importações de produtos.

Não deveria ser surpresa para ninguém a queda na produção, e muito menos o empobrecimento do homem ligado a essa lavoura e sua região de produção. Devem as políticas públicas, ligadas à derrocada da produção de algodão no Pontal do Paranapanema, serem vistas como relacionadas com a questão agrária na região? Parece-me evidente que sim, porém não é este o debate nacional. Nem os movimentos sociais - e muito menos o governo - relacionam, pelo menos não com prioridade, a questão agrária aos erros cometidos com essa lavoura.

A quase ausência de propostas e esforços para modernizar a extensão rural é fruto da falta de prioridade para esta causa. Sem uma importante alteração na educação tecnológica continuaremos a assistir a uma acelerada decadência do homem rural, em qualquer região, em todas as culturas.

Começa a existir um esforço para estabelecer uma política agrícola estável e consistente. $\mathrm{O}$ crédito rural está melhor, porém não equacionou adequadamente os erros passados, deixando sérios reflexos no presente. O seguro climático ainda é uma promessa. Os novos instrumentos de estabilização de preços estão em construção em um ritmo muitas vezes inferior à rápida falência e abandono dos antigos instrumentos.

A avaliação realizada para o Pontal do Paranapanema pode ser repetida em grandes áreas do Estado do Paraná, também em função da derrocada do algodão. Outras regiões e outras produções explicam o empobrecimento generalizado do homem do campo. É preciso relacionar o ambiente macroeconômico com a questão social, e procurar aqui soluções e atenuantes.

O que se entende por reforma agrária? Significa realizar reformas que alterem a estrutura social rural, promovendo a melhoria da qualidade de vida do homem do campo e a melhor distribuição de renda e de terras com sentido amplo, ou limita-se a tentar promover isto por meio das intervenções de desapropriações de terra e assentamentos de trabalhadores sem-terra? A questão parece simples, mas está longe de o ser.

Há consenso quanto à necessidade de promover reformas que alterem a triste questão social do campo. As divergências começam a ocorrer quando se discutem as maneiras, os métodos e as prioridades para a realização do interesse comum.

No Brasil, reforma agrária ainda significa, quase que de maneira exclusiva e certamente com elevadíssima prioridade, desapropriações e assentamentos. $\mathrm{O}$ debate nacional concentra-se nisto. Os agentes sociais oferecem total prioridade para essas intervenções, e o próprio governo montou um Ministério com esta finalidade. 
É preciso indagar: a prioridade para desapropriações e assentamentos equaciona a questão social? Não seria preciso trabalhar com amplitude, procurando maneiras e métodos - não só no discurso mas também com ações práticas e a necessária prioridade - que possam alterar a estrutura social do campo com maior eficiência e modernidade?

Os discursos melhoraram muito, incluindo hoje um grande número de fatores importantes para a questão social do campo. Entretanto, as ações dos movimentos sociais continuam priorizando desapropriações e assentamentos, e a política social do governo também permanece privilegiando-os. A reforma agrária restringese, assim, ao sentido tradicional e restrito do termo.

A conseqüência é a ausência de atenção e prioridade para as causas da marginalização social no campo. A destruição do algodão no Pontal ocorreu sem que os movimentos sociais se manifestassem, ou pelo menos sem que dirigissem uma pequena parte da importante mobilização política que possuem para ações contra a queda de produção e de apoio ao homem envolvido com esta lavoura.

Em 1992, participei de uma reunião no Pontal tentando equacionar o seguro climático da produção. Em 1997, ainda pensava ser possível inibir a concorrência do produto importado em condições desleais. Foram cinco anos de tentativas e de muito trabalho, e mais do que isto, de frustração com o isolamento. Faltaram recursos no orçamento para honrar o Proagro. Faltou vontade política para equacionar a concorrência dos importados. Faltou interesse da opinião pública quanto à derrocada da lavoura e a tragédia do homem a ela ligado.

Nesses cinco anos, a questão social do campo tornou-se prioridade internacional. Só faltou compreender que antes de tratar dos efeitos é preciso olhar as causas.

Mas na verdade, não é isso. No debate nacional, a relação causa-efeito da questão social do campo nada tem a ver com o ambiente macroeconômico. $\mathrm{O}$ debate concentra-se na terra. A questão social do Pontal ainda é vista como de posse ou propriedade. O poder público trata exclusivamente da terra. O movimento social pressiona pelos assentamentos. A opinião pública preocupa-se com o proprietário. Toda a atenção é concentrada na reforma tradicional. Questões como comércio exterior, política agrícola e extensão rural não encontram a prioridade que a posse da terra possui.

É preciso ampliar o debate. Reforma agrária precisa ser mais do que terra e, portanto, muito mais do que desapropriações e assentamentos, principalmente nas ações, mas também no discurso.

O processo de desenvolvimento brasileiro realizou, talvez, a maior urbanização do Ocidente: 100 milhões de habitantes nas cidades em meio século de desenvolvimento. O Brasil de hoje não pode ignorar esse passado recente, com profundas marcas ainda existentes.

As substituições de importações foram conseguidas por meio de uma série de 
políticas que privilegiaram o desenvolvimento das cidades e indústrias em relação ao campo. Na seqüência, vieram os incentivos às exportações industriais, que deram uma sobrevida ao modelo. Este esgotado, enfrentamos mais de uma década dedicada ao combate inflacionário. O campo recebeu, nesses cinqüenta anos, uma política de crédito rural subsidiado que, além de concentrador de renda, vazou em grande parte para os fornecedores de insumos e máquinas, deixando uma herança cuja marca atual é a securitização de dívidas.

O Brasil induziu o êxodo rural. No início, foram os câmbios múltiplos, nos quais a produção agrícola sempre ficou com o pior. A administração do comércio exterior pode ser lembrada pelos exemplos limites da reserva de mercado para a informática e das importações estatais de alimentos dos planos econômicos. A tributação setorial teve o discriminatório ICMS das exportações agrícolas corrigido somente agora. Investiu-se muito mais nas cidades, onde ainda encontramos escolas, hospitais e serviços públicos limitados.

A exaustão desse processo ocorreu antes da sua compreensão pela população. Os conceitos, e principalmente os preconceitos de meio século de desenvolvimento, são ainda muito presentes.

Iniciei, em 1990, um longo trabalho contra as importações de produtos agrícolas, em condições de concorrência desleal. Existiam dificuldades até mesmo para explicar do que estava falando. O plano Cruzado e as grandes importações de alimentos, realizadas pelo Estado, eram ainda muito recentes. Dumping, distorção por subsídio de governo estrangeiro, eram conceitos desconhecidos para uma população acostumada a uma economia autárquica. A regra era importar alimento barato, pretendendo influir nos índices que mediam o descontrole inflacionário, mesmo que destruindo a produção nacional e o homem a ela ligado.

O final da rodada Uruguai de negociações, no âmbito da Organização Mundial de Comércio, facilitou a divulgação de que as agriculturas dos países ricos eram pesadamente subsidiadas. Até isto era novidade em 1990. O Brasil entendia que se importavam alimentos da Europa e dos Estados Unidos porque eram mais baratos, e portanto de produtores mais eficientes.

Após uma longa trajetória, conseguimos oferecer uma proteção mínima para o leite. Primeiro, levantamos a legislação que introduziu no Brasil o conceito de direitos compensatórios por subsídios. Embora fosse suficiente para os casos de importações de produtos industriais, não era suficiente para a agricultura. Incluímos e aprovamos um artigo específico no que veio a se chamar de Lei Agrícola. Exigiu-se um decreto regulamentando o dispositivo da lei, e a seguir uma portaria regulamentando o já regulamentado. Após dois anos, muito trabalho e apoio geral da classe produtora, saiu a proteção, ainda que mínima.

O caso do trigo veio em seguida, e depois de uma breve vitória as importações vieram em massa, transformando radicalmente as regiões produtoras. $\mathrm{O}$ algodão merece detalhes. Primeiro, foi necessário provar que era subsidiado. Depois, 
provar o óbvio: que causara grandes danos à economia nacional. Decidiu-se, então, que embora subsidiado e causando danos, não havíamos provado a relação causal entre as importações e o dano. $\mathrm{O}$ algodão continua sem proteção.

Fomos acusados de protecionistas, como se dumping e subsídios fossem admissíveis em qualquer economia moderna. Alegou-se que faltava competitividade à lavoura. O pequeno agricultor do Pontal não conseguia vencer os apoios financeiros de governos estrangeiros. Seriam todos ineficientes?

Falava-se em novas variedades de sementes e em colheita mecanizada como se fôssemos obrigados a ter produtividade de sobra para suportar a concorrência das importações e os estímulos contrários do nosso governo. Ao mesmo tempo, a indústria do tecido de algodão, que já possuía $70 \%$ de alíquota de imposto de importação, foi ainda mais estimulada, recebendo do governo um regime de quotas.

A proteção do emprego da indústria mereceu, portanto, atenção do governo e apoio da sociedade. A proteção do emprego da lavoura de algodão, nesse caso somente contra concorrência desleal, não teve apoio. Ao mesmo tempo, pretendiase equacionar a questão social do homem do campo com prioridade para a intervenção tradicional, as desapropriações e os assentamentos. $\mathrm{O}$ alto interesse para a questão social do campo exigiria um mínimo de atenção para as importações de algodão. Infelizmente, no Brasil a reforma agrária está apenas relacionada à posse de terra.

Comparemos a política agrícola com o tipo de atenção que recebeu a indústria automobilística, setor certamente muito importante. Aqui sim aprovou-se uma política realmente protecionista. Se a questão social do campo é tão importante, não mereceria por parte do governo uma atenção, se não maior, ao menos igual?

Ao tratar a questão social do campo sendo como de exclusiva, ou pelo menos prioritária, responsabilidade da realmente injusta distribuição de terra, ignora-se causas reais de marginalização social. Os investimentos sociais em saúde, educação básica e tecnológica, os instrumentos de política agrícola e de comércio exterior, ficam em um longínquo segundo plano. Concentra-se no que é visto como a maneira de transformar a distribuição de terras. A prioridade é para a intervenção estatal na estrutura de propriedade, por meio de desapropriações e assentamentos.

Essa visão identifica como responsável pela triste situação social do campo a terra e, na seqüência, seu proprietário. Condená-lo torna-se prioridade. Os movimentos sociais de trabalhadores, o próprio governo e a opinião pública, nesta ordem, culpam o proprietário pela pobreza rural. Ignoram todo o processo de desenvolvimento e industrialização do país do passado e os graves erros do presente.

É interessante comparar a diferença entre as reações da opinião pública e dos governos sobre as invasões de propriedades, quer estejam no meio urbano ou rural. O movimento social dos trabalhadores sofreu forte reação contrária quando passou a estender para o meio urbano os métodos que utilizam no campo. Invadir em desrespeito à lei somente tem justificativa moral para a sociedade brasileira quando 
se trata do campo. Tem até outro nome, é ocupação. Invadir habitações ou supermercados continua sendo invasão e, portanto, permanece inaceitável.

A atuação dos movimentos sociais dos trabalhadores rurais foi enquadrada pela sociedade como desobediência civil e, como tal, com justificativa moral, apesar de conter ações ilegais. Pode-se quebrar a lei ao procurar corrigir uma injustiça, mesmo quando um governo escolhido em eleições justas falha em corrigir estas injustiças. O movimento estaria, assim, atuando no sentido de persuadir a sociedade a ver e sentir a injustiça.

Aparentemente, a sociedade justifica a transgressão no campo considerando o que vê como uma história - incluindo seus responsáveis - que criou grande pobreza para milhões. Também teria proporcionado vasto e injusto poder político a grandes proprietários, que estariam entravando o julgamento econômico e estratégico para a sociedade brasileira. A invasão de propriedade urbana, entretanto, não recebe esse enquadramento, como já vimos inúmeras vezes.

Transgredir a lei, desrespeitar o direito de propriedade, apenas no campo. Só é desobediência civil quando recai sobre o proprietário rural. As invasões de prédios públicos dos órgãos responsáveis pela reforma agrária tradicional até existem, mas são condenadas pelo governo. Desobediência civil sobre os responsáveis pelo comércio exterior, seguro rural, juros exorbitantes ou extensão rural, inexiste.

O Brasil é indiscutivelmente um país injusto. Seria mais injusto no campo do que na cidade? A estatística de que $1 \%$ da população detém $45 \%$ das terras é sempre lembrada. Uma sociedade democrática que não corrige essa distorção exigiria pressões ao arrepio do Estado de Direito para mudar. É preciso avaliar o uso de uma estatística que mistura terras agricultáveis com vastas extensões da região amazônica, com pouca ou nenhuma capacidade de produção, ou mesmo moradia, com a atual tecnologia. Infelizmente, a distribuição de renda no Brasil é ainda pior do que a de terras.

A proposta para atuar na distribuição de terras no que se chama de reforma agrária - e que chamo de reforma agrária tradicional - é praticamente a mesma para o governo, para o movimento social e para a sociedade brasileira. Insiste-se há muitas décadas em intervir por meio de desapropriações e assentamentos. A divergência recai sobre o número de assentamentos e desapropriações. Não seria isso um problema? Escolhido um método ineficiente, nunca se terá o necessário progresso, apesar de toda prioridade.

Dirá o movimento social que o método é eficiente, e que não caminha devido ao poder político dos grandes proprietários e à lentidão do Poder Judiciário. Dirá o governo que tem nesse método sua principal intervenção social no campo, que é o que a sociedade deseja.

Discordo disso, pois a lentidão da justiça é a mesma das cidades, e o volume de terras arrecadadas para a reforma agrária é muito maior do que a capacidade do Estado em organizá-las. Parece-me claro que o importante é sair desse impasse, 
ampliando as políticas públicas e os métodos de intervenção na procura por justiça social no campo, que é o que realmente a sociedade deseja.

Não se trata de conseguir que as invasões de propriedades rurais deixem de ter o apoio da sociedade, perdendo sua condição de desobediência civil. O que é preciso é modernizar rapidamente as políticas públicas, criando condições para que, de fato, as graves injustiças - tanto nas cidades como no campo - sejam corrigidas. A política é de apoio ao homem.

Ampliar o debate sobre a questão social do campo é o grande desafio. É preciso olhar para o futuro. Embora estejamos vivendo um período de grande tensão social, continuo com esperança. A experiência de ter participado, no Instituto de Estudos Avançados da USP, de intenso debate, dentro de uma metodologia inovadora que inibiu os preconceitos, confirmou minha visão sobre a questão social do campo. Os resultados foram muito claros. O debate nacional, concentrado em desapropriações e assentamentos, é muito pobre.

Em recente troca de correspondência com Noam Chomsky, intelectual que admiro desde meu tempo de mestrado no Massachusetts Institute of Technology, recebi novo estímulo. Ampliar o foco, passando a trabalhar questões fundamentais, é difícil em qualquer lugar do mundo. Não existem mágicas, apenas trabalho.

E há os que dizem que não fiz nada pela reforma agrária.

Resumo - Ampliar o debate sobre a questão social do campo é o grande desafio. É preciso olhar para o futuro. O que se entende por reforma agrária? Significa realizar reformas que alterem a estrutura social rural promovendo a melhoria da qualidade de vida do homem do campo e a melhor distribuição de renda e de terras com sentido amplo, ou limita-se a tentar promover isto por meio das intervenções de desapropriações de terra e assentamentos de trabalhadores sem-terra?

Abstract-To amplify the debate about social issues related to the countryside is a great challenge in Brazil. It is necessary to look at the future. What does land reform mean? Does it mean to make changes that would alter the rural social structure in order to promote the small farmer men' enhancement of life quality and a better income and land distribution in a wide sense? Or is it limited to try to promote changes by simply taking away farmers' land and by landless workers trespassing?

Pedro de Camargo Neto é doutor em Engenharia de Produção, coordenador do PNBE (Pensamento Nacional das Bases Empresariais) e ex-presidente da Sociedade Rural Brasileira. 